\title{
060
}

\section{DIAGNOSI DI INFEZIONI RESPIRATORIE DA BATTERI PATOGENI ATIPICI MEDIANTE REAL TIME PCR}

\author{
Riccabone A., Quaranta MR., Barbui A., Robbiano F., \\ Marchiaro G.
}

S.C. Microbiologia, Azienda ospedaliera "San Giovanni Battista di Torino", Corso Bramante 88, 10126 Torino

La PCR real time è un sistema di analisi del DNA con caratteristiche analitiche estremamente interessanti in termini di sensibilità e specificità, ma soprattutto di rapidità e semplicità d'uso. Nell'ambito dell'identificazione di batteri patogeni nei materiali biologici solo recentemente sono stati messi a punto sistemi commerciali standardizzati per la diagnosi di alcune infezioni batteriche. In questo studio abbiamo confrontato il Kit in real time PCR, LightCycler, Roche per la diagnosi di agenti batterici di polmoniti atipiche (L.pneumophila, M.pneumoniae e C.pneumoniae) con una tecnica di PCR nested ultrasensibile utilizzando il kit "Pneumotris" (Amplimedical divisione Bioline) e sono stati valutati la sensibilità, specificità e l'impatto nell'organizzazione del laboratorio. Sono stati analizzati in parallelo 68 campioni biologici delle vie respiratorie ( 8 espettorati, 11 broncoaspirati e 46 lavaggi bronco-alveolari, 3 biopsie polmonari), una serie di 8 diluizioni di DNA di un ceppo di riferimento di L. pneumophila gr1 per valutare la sensibilità, e 4 ceppi Legionella non pneumophila gruppo 1 per la specificità.

I risultati ottenuti sui campioni biologici mostrano una concordaza del $100 \%$ tra i due metodi. La valutazione della sensibilità con l'impiego delle diluizioni scalari del DNA di legionella mostra una sensibilià maggiore (1 copie/reazione contro 10 copie/reazione) della metodica in real time PCR. Il set di primers e sonda per legionella utilizzato, rivela la presenza di DNA di L.pneumophila di gruppo 2-14 e di Legionella spp (L.anisa), mentre la metodica di confronto in nested PCR non rivela il DNA di Legionella spp

I tempi di esecuzione dei due sistemi sono molto diversi: con la real time si hanno i risultati in meno di due ore (applicabile all'urgenza), mentre per la nested PCR sono necessarie almeno 6 ore. La metodologia LightCycler risulta semplice 
da eseguire, il software è di facile impiego e permette la lettura e l'interpretazione automatica dei risultati, da sottolineare la possibilità di effettuare l'analisi delle curve di melting degli amplificati ottenuti per un totale controllo della loro specificità. Per questi motivi e per le ottime performance ottenute, questo sistema si dimostra di grande applicabilità pratica alla diagnosi di laboratorio delle infezioni respiratorie da patogeni atipici. 